\title{
High-flow nasal cannula oxygen therapy versus non-invasive ventilation for chronic obstructive pulmonary disease patients after extubation: a multicenter, randomized controlled trial
}

Dingyu Tan ${ }^{1 \dagger}$, Joseph Harold Walline ${ }^{2 \dagger}$, Bingyu Ling ${ }^{1}$, Yan Xu${ }^{1}$, Jiayan Sun ${ }^{3 *}$, Bingxia Wang ${ }^{1}$, Xueqin Shan ${ }^{1}$, Yunyun Wang ${ }^{1}$, Peng Cao', Qingcheng Zhu', Ping Geng ${ }^{1,4}$ and Jun $\mathrm{Xu}^{5^{*}}$

\begin{abstract}
Background: High-flow nasal cannula (HFNC) oxygen therapy is being increasingly used to prevent postextubation hypoxemic respiratory failure and reintubation. However, evidence to support the use of HFNC in chronic obstructive pulmonary disease (COPD) patients with hypercapnic respiratory failure after extubation is limited. This study was conducted to test if HFNC is non-inferior to non-invasive ventilation (NIV) in preventing post-extubation treatment failure in COPD patients previously intubated for hypercapnic respiratory failure.
\end{abstract}

Methods: COPD patients with hypercapnic respiratory failure who were already receiving invasive ventilation were randomized to HFNC or NIV at extubation at two large tertiary academic teaching hospitals. The primary endpoint was treatment failure, defined as either resumption of invasive ventilation or switching to the other study treatment modality (NIV for patients in the NFNC group or vice versa).

Results: Ninety-six patients were randomly assigned to the HFNC group or NIV group. After secondary exclusion, 44 patients in the HFNC group and 42 patients in the NIV group were included in the analysis. The treatment failure rate in the HFNC group was $22.7 \%$ and $28.6 \%$ in the NIV group-risk difference of $-5.8 \%$ ( $95 \% \mathrm{Cl},-23.8-12.4 \%$, $p=0.535$ ), which was significantly lower than the non-inferior margin of $9 \%$. Analysis of the causes of treatment failure showed that treatment intolerance in the HFNC group was significantly lower than that in the NIV group, with a risk difference of $-50.0 \%(95 \% \mathrm{Cl},-74.6$ to $-12.9 \%, p=0.015)$. One hour after extubation, the mean respiratory rates of both groups were faster than their baseline levels before extubation $(p<0.050)$. Twenty-four hours after extubation, the respiratory rate of the HFNC group had returned to baseline, but the NIV group was still (Continued on next page)

\footnotetext{
* Correspondence: 32494845@qq.com; xujunfree@126.com

${ }^{\dagger}$ Dingyu Tan and Joseph Harold Walline contributed equally to this work. ${ }^{3}$ Pharmacy Department, Clinical Medical College of Yangzhou University, Northern Jiangsu People's Hospital, Yangzhou 225001, China

${ }^{5}$ Emergency Department, Peking Union Medical College Hospital, Chinese Academy of Medical Sciences, Beijing 100730, China

Full list of author information is available at the end of the article
}

C C The Author(s). 2020 Open Access This article is licensed under a Creative Commons Attribution 4.0 International License, which permits use, sharing, adaptation, distribution and reproduction in any medium or format, as long as you give appropriate credit to the original author(s) and the source, provide a link to the Creative Commons licence, and indicate if changes were made. The images or other third party material in this article are included in the article's Creative Commons licence, unless indicated otherwise in a credit line to the material. If material is not included in the article's Creative Commons licence and your intended use is not permitted by statutory regulation or exceeds the permitted use, you will need to obtain permission directly from the copyright holder. To view a copy of this licence, visit http://creativecommons.org/licenses/by/4.0/ The Creative Commons Public Domain Dedication waiver (http://creativecommons.org/publicdomain/zero/1.0/) applies to the data made available in this article, unless otherwise stated in a credit line to the data. 


\begin{abstract}
(Continued from previous page)
higher than the baseline. Forty-eight hours after extubation, the respiratory rates of both groups were not significantly different from the baseline. The average number of daily airway care interventions in the NIV group was 7 (5-9.3), which was significantly higher than 6 (4-7) times in the HFNC group $(p=0.006)$. The comfort score and incidence of nasal and facial skin breakdown of the HFNC group was also significantly better than that of the NIV group [7 (6-8) vs $5(4-7), P<0.001]$ and [0 vs 9.6\%, $p=0.027$, respectively.
\end{abstract}

Conclusion: Among COPD patients with severe hypercapnic respiratory failure who received invasive ventilation, the use of HFNC after extubation did not result in increased rates of treatment failure compared with NIV. HFNC also had better tolerance and comfort than NIV.

Trial registration: chictr.org (ChiCTR1800018530). Registered on 22 September 2018, http://www.chictr.org.cn/ usercenter.aspx

Keywords: Chronic obstructive pulmonary diseases, Respiratory failure, High-flow nasal cannula, Non-invasive ventilation, Pulmonary infection control window, Hypercapnia

\section{Introduction}

Chronic obstructive pulmonary disease (COPD) is one of the leading causes of death worldwide. Acute hypercapnic respiratory failure is a common serious complication of COPD, and invasive mechanical ventilation is often required for severe cases. Longer durations of invasive mechanical ventilation will increase the incidence of ventilator-associated pneumonia and difficulty weaning off ventilation $[1,2]$. Multiple studies have shown that a sequential strategy with non-invasive ventilation (NIV) using a pulmonary infection control (PIC) window as the switching point can reduce the duration of invasive ventilation in COPD patients and significantly improve prognosis [3, 4].

The success of NIV is closely related to the experience and abilities of the treating medical staff, the level of education and compliance of patients, and the performance of the NIV device $[5,6]$. Due primarily to poor patient tolerance, NIV fails in approximately 15 to $25 \%$ of patients, potentially leading to endotracheal intubation [7-9]. For post-extubation patients with COPD who cannot tolerate NIV or have contraindications to NIV, alternative respiratory support methods are urgently needed.

High-flow nasal cannula (HFNC) oxygen therapy is a new type of respiratory support system which can supply high flow mixed gases through special nasal prongs at a sufficient temperature and humidity for patient comfort. Many studies have confirmed that the comfort and tolerance of HFNC is significantly higher than that of NIV [10-12]. As an alternative to NIV, HFNC has been shown to be as efficacious as NIV in preventing post-extubation respiratory failure or re-intubation in patients with hypoxemic respiratory failure [13, 14]. However, the postextubation application of HFNC in COPD patients with hypercapnic respiratory failure has not been widely studied. In a pilot study, HFNC was reported to maintain similar patient vital signs and arterial blood gases as NIV in post-extubated hypercapnic COPD patients [15].
This trial was conducted to test the hypothesis that HFNC immediately after extubation is non-inferior to NIV in reducing treatment failure in COPD patients previously intubated for hypercapnic respiratory failure.

\section{Materials and methods \\ Study design and ethical approval}

This was a multicenter, unblinded, non-inferiority, randomized controlled trial, registered at chictr.org (ChiCTR1800018530). From January 2019 to February 2020, the study was performed in the intensive care units (ICUs) of two large tertiary-care hospitals. This study was approved by the human subjects ethics committees of the two hospitals involved (2018KY-081 and 20180012), and informed consent was obtained from all enrolled patients or their relatives.

\section{Screening of patients}

COPD patients with hypercapnic respiratory failure who received invasive ventilation were screened for enrollment. The diagnosis of COPD was established according to the GOLD criteria [16]. Other inclusion criteria included patients who were $\leq 85$ years of age, able to care for themselves within the past year, respiratory failure induced by broncho-pulmonary infection, and meeting criteria of the PIC window. Exclusion criteria were age less than 18 years; lacking informed consent; contraindications to NIV (oral or facial trauma, poor sputum excretion ability, hemodynamic instability); poor shortterm prognosis (high risk of death within7 days or receiving palliative treatment); heart, brain, liver, or kidney failure; tracheotomy; or a weak cough ability during the PIC window.

The following types of patients were secondarily excluded: withdrawn informed consent, loss to followup, uncertain 28-day survival, discharge from hospital within $48 \mathrm{~h}$ after enrollment, and patients who refused to use their assigned device. 


\section{Experimental procedure}

The settings of the enrolled patients' invasive mechanical ventilation were adjusted by the attending physician according to the patient's ventilation status and blood gas analysis. The patients were randomly divided into the HFNC group and the NIV group when the PIC window appeared. Randomization was performed using a computer-generated random number generator, and allocation was concealed through an opaque envelope. These envelopes were kept in permuted blocks of ten, five each for NIV and HFNC, to ensure an even distribution of subject numbers in both groups at both centers.

All subjects receiving NIV (Philips V60 or BiPap Vision) were set in S/T mode with a standard oral-nasal (full-face) mask (RT040). NIV settings were adjusted with an adaptive method: the initial expiratory pressure airway pressure was set to $4 \mathrm{cmH}_{2} \mathrm{O}$, and the pressure level was gradually increased to ensure that the patient could trigger the NIV device with each inhalation. The inspiratory airway pressure was initially set to $8 \mathrm{cmH}_{2} \mathrm{O}$ and gradually increased to achieve a satisfactory tidal volume with acceptable tolerance. The pressure level and the fraction of inspiration oxygen $\left(\mathrm{FiO}_{2}\right)$ were adjusted to maintain a respiratory rate $\leq 28 / \mathrm{min}$, a pulse oxygen saturation $\left(\mathrm{SpO}_{2}\right)$ of $88-92 \%$, and a partial pressure of arterial carbon dioxide $\left(\mathrm{PaCO}_{2}\right)$ of either $45-60 \mathrm{mmHg}$ or the last $\mathrm{PaCO}_{2}$ level recorded prior to extubation.

Subjects randomized to the HFNC group (AIRVO ${ }^{\mathrm{mi}}$ 2, Fisher \& Paykel Healthcare, Auckland, New Zealand) were given suitable large-bore nasal prongs selected according to the size of the patients' nostrils. The initial airflow was set at $50 \mathrm{~L} / \mathrm{min}$ and adjusted according to patient tolerance. The HFNC was set to an absolute humidity of $44 \mathrm{mg} \mathrm{H}_{2} \mathrm{O} / \mathrm{L}$, temperature was set to $37^{\circ} \mathrm{C}$, and $\mathrm{FiO}_{2}$ was adjusted to maintain an $\mathrm{SpO}_{2}$ of $88-92 \%$.

The patient's initial respiratory support was targeted to last at least $2 \mathrm{~h}$ and then continued as needed. Nasal cannula oxygen was administered during any interruptions to NIV. NIV or HFNC were discontinued when the total daily treatment duration was less than $4 \mathrm{~h}$ and could be reused if needed. Treatment success was defined as no need for respiratory support within $72 \mathrm{~h}$ after stopping NIV or HFNC.

\section{Outcomes}

The primary outcome was treatment failure, defined as a return to invasive mechanical ventilation, or a switch in respiratory support modality (i.e., changing from HFNC to NIV or from NIV to HFNC). Secondary outcomes included arterial blood gas analysis $\left[\mathrm{pH}, \mathrm{PaO}_{2}\right.$ (partial pressure of oxygen in arterial blood), $\mathrm{PaCO}_{2}$, and $\mathrm{FiO}_{2}$ ] and vital signs such as respiratory rate, heart rate, and blood pressure at 1, 24, and $48 \mathrm{~h}$ after extubation, as well as the total duration of respiratory support after extubation, the daily number of nursing airway care interventions, the patients' comfort score, the patients' dyspnea score, the incidence of nasofacial skin breakdown, 28-day mortality, and total ICU and hospital lengths of stay.

Airway care interventions were defined as the need for nursing staff to correct unplanned device displacement due to intolerance, discomfort, or another reason, or the need for nursing staff to assist in the removal or fixation of the device due to sputum, eating, or drinking. The patient's comfort score was assessed using a modified $10-\mathrm{cm}$ visual analog scale, in which 1 meant very uncomfortable and 10 meant very comfortable [11]. The patients' dyspnea was evaluated with a Borg rating scale [17]. The criteria for reintubation in this study were $[18,19]$ cardiac arrest or obvious hemodynamic instability, refractory hypoxemia $\left(\mathrm{PaO}_{2}<50 \mathrm{mmHg}\right.$ with sufficient oxygen therapy), significant hypercapnia with $\mathrm{pH} \leq 7.20$, severe disturbances of consciousness such as coma, respiratory depression (respiratory frequency $<8 / \mathrm{min}$ ), or severe dyspnea (respiratory frequency $>40 / \mathrm{min}$ ).

\section{Sample size and statistical analysis}

Based on previous studies [20, 21], we estimated that NIV would fail in $22 \%$ patients (either intubation or intolerance) of included COPD patients, and the absolute difference of treatment failure rates between HFNC and NIV was likely to fall between 4 and 12\% [14]. After discussions with three senior pulmonologists, we set the non-inferiority cutoff at $9 \%$. To assess non-inferiority using an $\alpha=0.50, \beta=0.20$, and 1-sided testing, 44 subjects were needed in each group (88 total).

For the primary outcome, analysis was performed both on an intention-to-treat and on a per-protocol basis. The Kaplan-Meier method was used to draw the cumulative survival and failure curves. The Kolmogorov-Smirnov test was used to test the normal distribution for measurement data. Normally distributed data were expressed as means \pm standard deviation, and the skewed distributed data was reported as medians with interquartile (25th-75th) percentiles. The two groups were compared using $t$ tests or Mann-Whitney $U$ tests. Numeric data were expressed as a percentage (\%), using $X^{2}$ or Fisher's exact probability tests. The comparison of vital signs and blood gas analyses at multiple time points was performed by repeated measures analysis of variance, or non-parametric test of multiple correlated samples (Friedman test for heterogeneity of variance or the skewed distributed data), in which the significance level was adjusted using the Bonferroni correction method. All data analysis was conducted using SPSS 26.0 (IBM Corporation, Armonk, NY, USA).

\section{Results}

\section{Patient characteristics}

Among 149 COPD patients who received invasive ventilation in our enrolling centers during the study period, 
96 (64.4\%) patients were randomized to the NIV or HFNC groups after 53 patients were excluded for various reasons (see Fig. 1). Six patients in the NIV group and four patients in the HFNC group were secondarily excluded. Finally, 42 patients in the NIV group and 44 patients in the HFNC group were included in the analysis. Demographic, relevant comorbidities, smoking history, COPD medications, respiratory therapy at home, available pulmonary function tests, the Simplified Acute Physiology Score II (SAPS II), and the Acute Physiological and Chronic Health Status Score II (APACHE II) at admission in the two groups were similar (see Table 1). Seventeen (38.6\%) patients in the HFNC group and 18 (42.9\%) in the NIV group initially received NIV or HFNC after admission before invasive ventilation, and the remaining patients received invasive ventilation directly. There were also no significant differences in respiratory parameters, blood gas analyses, and vital signs between the two groups at the time of enrollment (PIC window before extubation). The stable $\mathrm{FiO}_{2}$ after extubation in the HFNC group was $0.32(0.28-0.38)$, which was not significantly different from $0.35(0.30-0.40)$ in the NIV group.

\section{Primary outcome}

Treatment failure occurred in 10 patients $(22.7 \%)$ in the HFNC group and 12 patients $(28.6 \%)$ in the NIV group (risk difference, $-5.8 \%$; 95\% CI, -23.8 to $12.4 \%$; see Table 2). Additionally, Kaplan-Meier curves showed no statistical difference in cumulative failure rates between the two groups (log-rank test 0.521, $p=0.470$, see Fig. 2). Among the patients with treatment failure, the intubation rate in the HFNC group was similar to that of the NIV group ( $-0.65 \%$; $95 \% \mathrm{CI},-16.01$ to $14.46 \%)$, and the treatment switch rate was lower than that in the NIV group (- 5.2\%; 95\% CI, -19.82 to $9.05 \%)$. However, there were no significant differences between the two groups in intubation or treatment switch rate.

Analysis of the causes of treatment failure showed that treatment intolerance was significantly lower in the HFNC group than in the NIV group, with a risk difference of $-50.0 \%(95 \% \mathrm{CI},-74.6$ to $-12.9 \%, p=0.015$, see Table 2). There was no significant difference between the two groups in exacerbated respiratory distress, hypoxemia, or carbon dioxide retention. The causes for six intolerances in the NIV group were feelings of

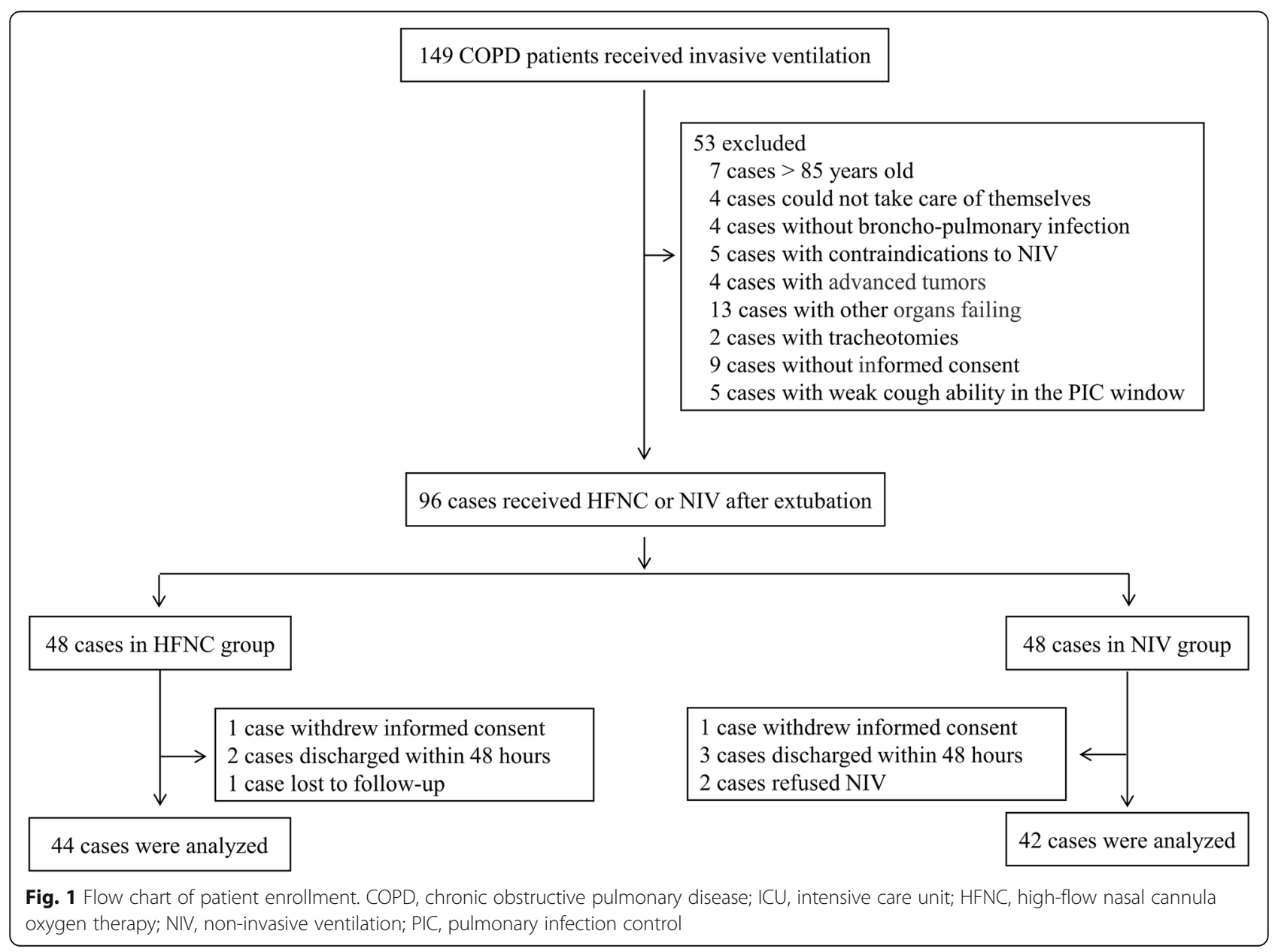


Table 1 Characteristics of enrolled patients

\begin{tabular}{|c|c|c|c|}
\hline Characteristics & HFNC $(n=44)$ & NIV $(n=42)$ & $p$ value \\
\hline Male, $n(\%)$ & $27(64.3)$ & $23(55.6)$ & 0.259 \\
\hline Age, years & $68.4 \pm 9.3$ & $71.4 \pm 7.8$ & 0.107 \\
\hline History of COPD, years & $8(5.3-10)$ & $10(6-12.3)$ & 0.063 \\
\hline Smoking history, $n(\%)$ & $20(45.5)$ & $26(61.9)$ & 0.126 \\
\hline Current & $8(45.5)$ & $11(45.5)$ & 0.371 \\
\hline \multicolumn{4}{|l|}{ Comorbidities, $n(\%)$} \\
\hline Diabetes mellitus & $10(22.7)$ & $14(33.3)$ & 0.273 \\
\hline Hypertension & $25(56.8)$ & $17(40.5)$ & 0.130 \\
\hline Coronary artery disease & $13(29.5)$ & $16(38.1)$ & 0.402 \\
\hline Chronic liver disease & $2(4.5)$ & $5(11.9)$ & 0.260 \\
\hline Chronic kidney disease & $12(27.3)$ & $8(19.0)$ & 0.367 \\
\hline Cerebrovascular disease & $5(11.4)$ & $7(16.7)$ & 0.545 \\
\hline Malignancy & $6(13.6)$ & $3(7.1)$ & 0.325 \\
\hline \multicolumn{4}{|c|}{ Medication before exacerbation, $n(\%)$} \\
\hline Inhaled corticosteroids & $11(30.8)$ & $15(34.9)$ & 0.280 \\
\hline Beta adrenoceptor agonist & 17 (38.6) & $11(26.2)$ & 0.218 \\
\hline Anticholinergics & $5(11.4)$ & $8(19.0)$ & 0.320 \\
\hline \multicolumn{4}{|l|}{ Home oxygen therapy, $n(\%)$} \\
\hline NCO & $8(18.2)$ & $5(11.9)$ & 0.417 \\
\hline NIV & $5(11.4)$ & $7(16.7)$ & 0.478 \\
\hline \multicolumn{4}{|c|}{ Lung function test before exacerbation $(n=52)^{*}$} \\
\hline $\mathrm{FEV}_{1}, \%$ & $41.3 \pm 11.0$ & $43.2 \pm 12.6$ & 0.577 \\
\hline $\mathrm{FEV}_{1} / \mathrm{FVC}, \%$ & $40.9 \pm 9.8$ & $42.4 \pm 9.6$ & 0.580 \\
\hline APACHE II score & $14(11-18.8)$ & $13(10.8-16)$ & 0.323 \\
\hline SAPS II score & $27(22-32.8)$ & $30(24-34.8)$ & 0.138 \\
\hline \multicolumn{4}{|l|}{ NIV or HFNC before IMV, $n(\%)$} \\
\hline NIV & $10(22.7)$ & $13(31.0)$ & 0.389 \\
\hline HFNC & $7(15.9)$ & $5(11.9)$ & 0.592 \\
\hline \multicolumn{4}{|l|}{ Characteristics at the PIC window } \\
\hline Pressure support, $\mathrm{cmH}_{2} \mathrm{O}$ & $11.7 \pm 2.0$ & $11.5 \pm 1.7$ & 0.584 \\
\hline PEEP, $\mathrm{cmH}_{2} \mathrm{O}$ & $5.5(5-6)$ & $6(5-6)$ & 0.512 \\
\hline Tidal volume, mL & $442.7 \pm 57.7$ & $431.2 \pm 51.9$ & 0.333 \\
\hline Minute volume, L/min & $8.5 \pm 2.0$ & $9.1 \pm 2.5$ & 0.292 \\
\hline Respiratory frequency, /min & $18(16-23)$ & $21(16-26)$ & 0.158 \\
\hline Arterial pH & $7.48(7.42-7.51)$ & $7.45(7.40-7.49)$ & 0.102 \\
\hline $\mathrm{PaCO}_{2}, \mathrm{mmHg}$ & $50.5(48-57.8)$ & $53(48.8-61.3)$ & 0.236 \\
\hline $\mathrm{PaO}_{2} / \mathrm{FiO}_{2}, \mathrm{mmHg}$ & $239.2 \pm 47.0$ & $229.3 \pm 42.0$ & 0.307 \\
\hline Heart rate, beats/min & $92(80.5-107.8)$ & $87.5(80.8-101.5)$ & 0.362 \\
\hline Mean arterial pressure, mmHg & $88 \pm 6.0$ & $84.5 \pm 10.3$ & 0.057 \\
\hline Duration of IMV, hours & $98(65.8-175.8)$ & $114(79.3-147.5)$ & 0.792 \\
\hline $\mathrm{FiO}_{2}$ after extubation (stable) & $0.32(0.28-0.38)$ & $0.35(0.30-0.40)$ & 0.447 \\
\hline
\end{tabular}

Data are shown as means \pm standard deviation, number (\%) patients, or median (interquartile range)

HFNC high-flow nasal cannula oxygen therapy, NIV non-invasive ventilation, COPD chronic obstructive pulmonary disease, NCO nasal cannula oxygen, ICU intensive care unit, APACHE II Acute Physiology and Chronic Health Evaluation II, SAPS II Simplified Acute Physiology Score II, IMV invasive mechanical ventilation, $\mathrm{PIC}$ pulmonary infection control, $\mathrm{PEEP}$ positive end expiratory pressure, $\mathrm{PaCO}_{2}$ partial pressure of arterial carbon dioxide, $\mathrm{PaO}{ }_{2}$ partial pressure of arterial oxygen, $\mathrm{FiO}_{2}$ fraction of inspiration oxygen

${ }^{*}$ Twenty-five cases in the HFNC group and 27 cases in the NIV group 
Table 2 Primary outcome and cause analysis

\begin{tabular}{|c|c|c|c|c|}
\hline & HFNC $(n=44)$ & NIV $(n=42)$ & Risk difference, \% (95\% Cl) & $p$ value \\
\hline \multicolumn{5}{|l|}{ Primary outcome, $n(\%)$} \\
\hline Treatment failure & $10(22.7)$ & $12(28.6)$ & $-5.8(-23.8$ to 12.4$)$ & 0.535 \\
\hline Invasive ventilation & $6(13.6)$ & $6(14.29)$ & $-0.65(-16.01$ to 14.46$)$ & 0.931 \\
\hline Treatment switch & $4(9.1)$ & $6(14.3)$ & $-5.2(-19.82$ to 9.05$)$ & 0.516 \\
\hline \multicolumn{5}{|l|}{ Analysis of treatment failure, $n(\%)$} \\
\hline Treatment intolerance & $0 / 10(0)$ & $6 / 12(50.0)$ & $-50.0(-74.62$ to -12.9$)$ & 0.015 \\
\hline Aggravation of respiratory distress & $5 / 10(50)$ & $2 / 12(16.67)$ & $33.33(-5.21$ to 62.27$)$ & 0.172 \\
\hline Aggravation of hypoxemia & $2 / 10(20)$ & $1 / 12(8.33)$ & $11.67(-18.95$ to 43.4$)$ & 0.571 \\
\hline Aggravation of carbon dioxide retention & $3 / 10(30)$ & $3 / 12(25)$ & $5(-29.15$ to 39.33$)$ & 1.0 \\
\hline
\end{tabular}

HFNC high-flow nasal cannula oxygen therapy, NIV non-invasive ventilation

claustrophobia $(n=2)$, excessive air flow or pressure $(n=2)$, breathlessness $(n=1)$, and headache $(n=1)$.

\section{Secondary outcomes \\ Vital signs and blood gas analyses}

Heart rate and mean arterial pressure within $48 \mathrm{~h}$ after extubation in the two groups were not significantly different from baseline levels before extubation. Respiratory rate in both groups was faster than before extubation at $1 \mathrm{~h}$ after extubation $(p<0.050$, see Table 3$)$. The respiratory rate $24 \mathrm{~h}$ after extubation in the HFNC group had decreased to its baseline and was lower than the respiratory rate in the NIV group [20 (17.3-24.5)/min vs 24.5 $(18-27) / \mathrm{min}, p<0.050]$. The NIV group's respiratory rate was also higher than its baseline level. There was no significant difference in respiratory rate between the two groups at $48 \mathrm{~h}$ after extubation.

Arterial blood gas analyses showed that the $\mathrm{PaO}_{2} / \mathrm{FiO}_{2}$ and $\mathrm{pH}$ values in the HFNC group were lower than their baseline levels, while $\mathrm{PaCO}_{2}$ was higher than the baseline level $1 \mathrm{~h}$ after extubation (all $p<0.050$, see Table 3 ). The $\mathrm{PaO}_{2} / \mathrm{FiO}_{2}, \mathrm{pH}$, and $\mathrm{PaCO}_{2}$ in the HFNC and NIV groups $24 \mathrm{~h}$ and $48 \mathrm{~h}$ after extubation were not statistically different from the baseline levels.

\section{Other outcomes}

There were no significant differences in the duration of post-extubation respiratory support, dyspnea scores, ICU, or hospital total lengths of stay between the two groups (all $p<0.050$, see Table 4 ). The 28-day mortality in the HFNC group was $15.9 \%$, which was not significantly different from the $11.9 \%$ in the NIV group (logrank test $0.288, p=0.591$, see Fig. 3 ). The number of daily airway care interventions was significantly lower in the HFNC group than in the NIV group [6 (4-7) vs 7 (5-9.3), $p=0.006]$. The comfort score in the HFNC group was also significantly higher than that in the NIV group [7 (6-8) vs $5(4-7), p<0.001$ ], whereas the incidence of nasofacial skin breakdown was significantly lower in the HFNC group than in the NIV group (0 vs $9.6 \%, p=0.027)$.

\section{Discussion}

This multicenter, randomized controlled trial showed that HFNC was not inferior to NIV at preventing postextubation treatment failure and re-intubation for COPD patients recently extubated after hypercapnic respiratory failure. Compared with NIV, HFNC was more comfortable and better tolerated. The number of airway care interventions and the incidence of nasofacial skin breakdown associated with HFNC were significantly lower than in NIV. HFNC appears to be an effective means of respiratory support for COPD patients extubated after severe hypercapnic respiratory failure.

Invasive ventilation is sometimes necessary to rescue COPD patients with severe hypercapnic respiratory failure. Weaning strategies which include NIV are recommended as the standard treatment to reduce rates of ventilator-associated pneumonia and mortality without increasing the risk of re-intubation or weaning failure [22]. However, NIV intolerance appears in more than $15 \%$ patients due to various reasons, which increases the risk of treatment failure and re-intubation [23, 24]. Like in this study, many others have found that HFNC is often better tolerated than NIV, but data on COPD patients so far has been limited.

HFNC has been increasingly suggested for use in patients with COPD with acute hypercapnic respiratory failure. Bräunlich et al. reported that in 38 patients with an acute exacerbation of COPD and a $\mathrm{pH}$ of less than 7.38, HFNC increased the $\mathrm{pH}$ by 0.052 and reduced carbon dioxide by $9.1 \mathrm{mmHg}$ [25]. In a prospective observational study involving 30 patients with moderate hypercapnic respiratory failure who were intolerant to NIV, patients' $\mathrm{pH}$ improved and respiratory rate decreased with HFNC treatment, and the non-response rate to HFNC was only $13.3 \%$ [26]. Subsequently, two cohort studies with larger samples showed that for 


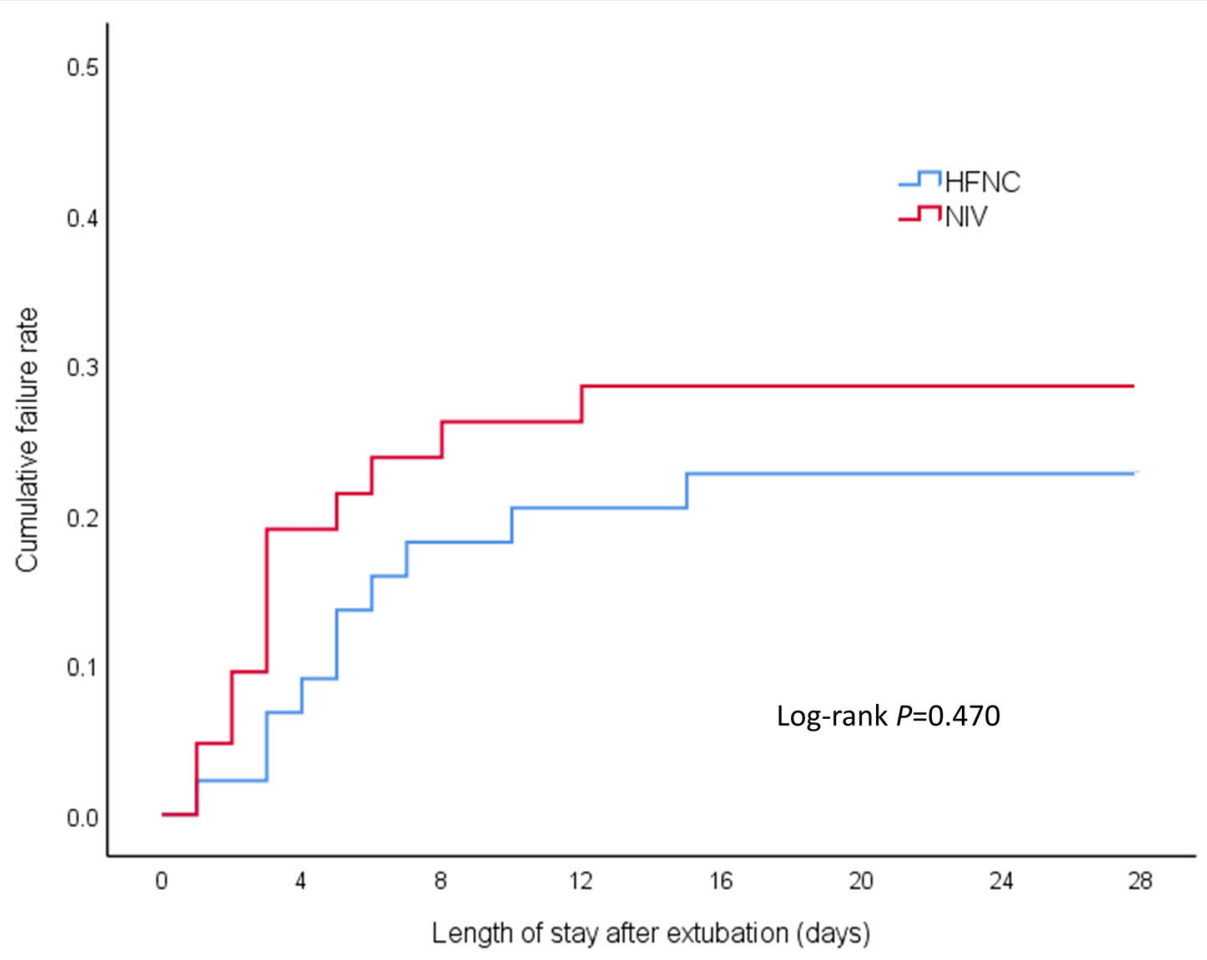

Fig. 2 Kaplan-Meier curve analysis for cumulative failure rate. HFNC, high-flow nasal cannula oxygen therapy; NIV, non-invasive ventilation

COPD patients with acute moderate hypercapnic respiratory failure, similar tracheal intubation and mortality rates were observed between HFNC and NIV, while HFNC was better tolerated [27, 28].

Other efforts to observe the efficacy of HFNC in COPD patients after invasive ventilation have been limited. In a cross-over study comparing HFNC to conventional low-flow oxygen therapy, HFNC was found to significantly decrease post-extubation work of breathing and neuroventilatory drive in COPD patients recovering from acute hypercapnic respiratory failure [29]. In a small randomized controlled trial, hypercapnic COPD

Table 3 Vital signs and arterial blood gas analysis

\begin{tabular}{|c|c|c|c|c|c|c|}
\hline & $\mathrm{HR}(\mathrm{bpm})$ & $\mathrm{MAP}(\mathrm{mmHg})$ & RR (bpm) & $\mathrm{pH}$ & $\mathrm{PaCO}_{2}(\mathrm{mmHg})$ & $\mathrm{PaO}_{2} / \mathrm{FiO}_{2}(\mathrm{mmHg})$ \\
\hline \multicolumn{7}{|l|}{$\mathrm{NIV}(n=42)$} \\
\hline Baseline & $87.5(80.8-101.5)$ & $84.5 \pm 10.3$ & $21(16-26)$ & $7.45(7.40-7.49)$ & $53(48.8-61.3)$ & $229.3 \pm 42.0$ \\
\hline $1 \mathrm{~h}$ & $90.5(80-108.3)$ & $86.8 \pm 10.2$ & $25.5(18-28)^{*}$ & $7.44(7.39-7.48)$ & $55(48.8-61.3)$ & $218.9 \pm 37.8^{*}$ \\
\hline $24 \mathrm{~h}$ & $94(79.8-105.3)$ & $87.6 \pm 11.1$ & $24.5(18-27)^{*}$ & $7.45(7.41-7.48)$ & $52.5(49-57.3)$ & $222.4 \pm 34.5$ \\
\hline $48 \mathrm{~h}$ & $93.5(79.5-107.5)$ & $87.7 \pm 12.6$ & 21.5 (16.8-26) & $7.45(7.41-7.48)$ & $52(49-56)$ & $227.2 \pm 40.5$ \\
\hline$p$ value ${ }^{a}$ & 0.083 & 0.097 & 0.000 & 0.884 & 0.542 & 0.002 \\
\hline \multicolumn{7}{|c|}{ HFNC $(n=44)$} \\
\hline Baseline & $92(80.5-107.8)$ & $88 \pm 6.0$ & $18(16-23)$ & $7.48(7.42-7.51)$ & $50.5(48-57.8)$ & $239.2 \pm 47.0$ \\
\hline $1 \mathrm{~h}$ & $94.5(86-103.8)$ & $89.7 \pm 7.9$ & $21(18-25)^{*}$ & $7.42(7.40-7.48)^{*}$ & $56(49.3-59)^{*}$ & $220.5 \pm 36.3^{*}$ \\
\hline $24 \mathrm{~h}$ & 93 (80.3-99.8) & $87.0 \pm 8.8$ & $20(17.3-24.5)^{\#}$ & $7.44(7.41-7.48)$ & $54(49-58)$ & $228.4 \pm 35.3$ \\
\hline $48 \mathrm{~h}$ & $92(82.3-103.3)$ & $86.1 \pm 8.1$ & $19(16.3-23.8)$ & $7.43(7.41-7.49)$ & $51(49-57.8)$ & $230.3 \pm 36.0$ \\
\hline$p$ value $^{a}$ & 0.454 & 0.129 & 0.009 & 0.002 & 0.016 & 0.000 \\
\hline
\end{tabular}

Data are shown as means \pm standard deviation or median (interquartile range)

$H F N C$ high-flow nasal cannula oxygen therapy, $N I V$ non-invasive ventilation, $H R$ heart rate, $M A P$ mean arterial pressure, $R R$ respiratory rate, $P a C O_{2}$ partial pressure of arterial carbon dioxide, $\mathrm{PaO}_{2}$ partial pressure of arterial oxygen, $\mathrm{FiO}_{2}$ fraction of inspiration oxygen

${ }^{*}$ Compared with the baseline value in the same group, $p<0.05$ after Bonferroni correction

\#Compared with NIV at the same time point, $p<0.05$

${ }^{a}$ Comparison of multiple time points within the group 
Table 4 Other outcomes in the HFNC and NIV groups

\begin{tabular}{llll}
\hline & HFNC $(n=44)$ & NIV $(n=42)$ & $p$ value \\
\hline Duration of HFNC or NIV, hours & $83.9 \pm 33.1$ & $70.9 \pm 30.6$ & 0.063 \\
Airway care interventions, per day & $6(4-7)$ & $7(5-9.3)$ & 0.006 \\
Comfort score & $7(6-8)$ & $5(4-7)$ & 0.000 \\
Dyspnea score & $3(2-4)$ & $2(2-3)$ & 0.136 \\
Nasal facial skin breakdown, $n(\%)$ & $0(0)$ & $5(9.6)$ & 0.027 \\
Length of stay in ICU, days & $7.5(6-10)$ & $8.5(6-12.3)$ & 0.324 \\
Length of stay in hospital, days & $10(8.3-12)$ & $11(9-14.3)$ & 0.245 \\
28-day mortality, $n(\%)$ & $7(15.9)$ & $5(11.9)$ & 0.758 \\
\hline
\end{tabular}

Data are shown as means \pm standard deviation, number (\%) patients, or median (interquartile range)

HFNC high-flow nasal cannula oxygen therapy, NIV non-invasive ventilation ICU intensive care unit

patients received either HFNC or NIV immediately after extubation [15]. At 3 and $24 \mathrm{~h}$ after extubation, the $\mathrm{pH}$ in the HFNC group was higher than NIV group. No significant differences of vital signs and arterial blood gases were found at $48 \mathrm{~h}$ after extubation.

Unlike in the above study, the respiratory rate in both groups of our study increased at $1 \mathrm{~h}$ after extubation, which may be related to the relatively lower intensity of respiratory support after extubation. The respiratory rate in the HFNC group decreased to its baseline level $24 \mathrm{~h}$ after extubation, while the respiratory rate in the NIV group was still high at $24 \mathrm{~h}$. This can be explained by the relatively poor tolerance of NIV and the increase in effective alveolar ventilation caused by the washout effect of dead space in HFNC.

One hour after extubation, the $\mathrm{pH}$ in the HFNC group of this study decreased and the $\mathrm{PaCO}_{2}$ increased, while the NIV group had no significant change from its baseline level. The difference between the two groups may be because HFNC does not have the added pressure support of NIV, resulting in decreased ventilation and oxygenation. However, the excellent tolerance and increased effective alveolar ventilation gradually made up for the above deficiencies, so that there was no significant difference in blood gas values between the two groups at 24 and $48 \mathrm{~h}$ after extubation.

To the best of our knowledge, this is the first randomized controlled trial to compare the failure rate of HFNC and NIV in patients with COPD after invasive ventilation. Treatment failure in this study was defined as reintubation or switch to the other treatment modality. Although the latter criterion added an element of patient subjectivity to the definition, this composite end-point reflects the pragmatic application of HFNC or NIV in everyday clinical practice [30]. Analysis of the causes of treatment failure in this study showed that treatment intolerance was significantly higher in the NIV group than in the HFNC group, suggesting that poor tolerance is an important reason for the failure of NIV treatment. Doshi et al. also found that $29 \%$ of NIV failures were attributed to treatment intolerance, which was significantly higher than the $4 \%$ rate of HFNC [31]. HFNC's design does not

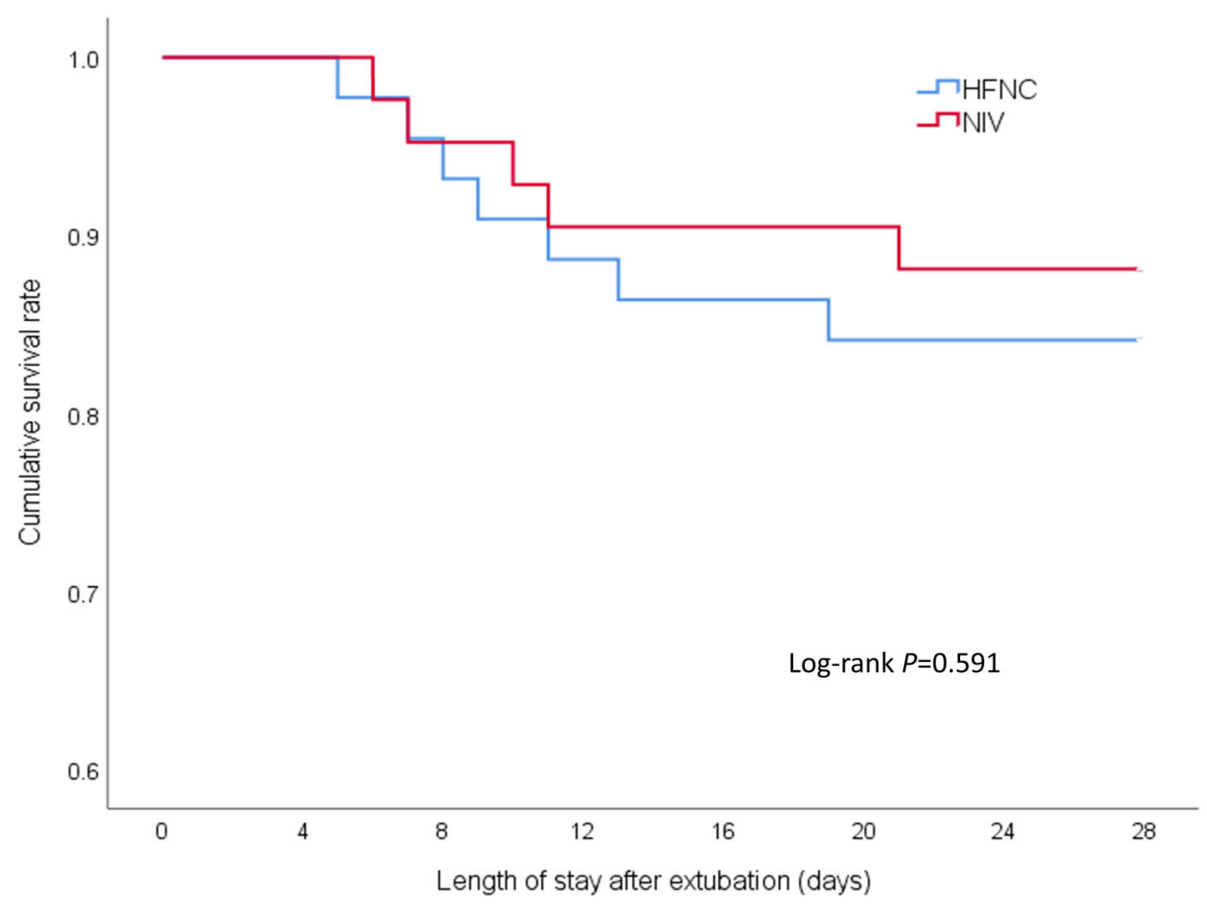

Fig. 3 Kaplan-Meier curve analysis for cumulative survival rate. HFNC, high-flow nasal cannula oxygen therapy; NIV, non-invasive ventilation 
lead to a sense of claustrophobia, which significantly improves compliance. At the same time, the heating and humidifying function of HFNC enables the gas delivered to reach an absolute humidity of $44 \mathrm{mg} \mathrm{H}_{2} \mathrm{O} / \mathrm{L}$ and a temperature of $37^{\circ} \mathrm{C}$, which effectively promotes the discharge of secretions while avoiding side effects such as dry mucous membranes [32]. Because of these characteristics, patients can easily tolerate a gas flow rate of up to $50-60 \mathrm{~L} / \mathrm{min}$. The better tolerance of HFNC over NIV is clearly seen in comparing the comfort scores between the two groups.

The number of airway care interventions and cases of nasofacial skin breakdown in the HFNC group were also significantly lower than those in the NIV group, which was related to the HFNC nasal plug design and better comfort. Due to intolerance, drinking and eating, sputum clearance, communication, discomfort, or displacement of the NIV mask, NIV patients frequently remove their masks and significantly increase the nursing workload [28]. Patients in the HFNC group were not restricted by respiratory support in eating, drinking, and communicating. The incidence of skin breakdown and displacement of nasal prongs was extremely low.

There were some limitations to this study. First, the primary endpoint of this study was a composite of reintubation rate and switching to the other treatment modality, which has potential limitations described above. As for the re-intubation rate, the possibility of obtaining a positive result by increasing the sample size cannot be ruled out. Second, the settings for the HFNC gas flow in this study were based on each patient's tolerance level, which is subjective. In subsequent studies, the HFNC gas flow could be titrated through diaphragmatic potential or ultrasound assessment of diaphragmatic muscle movement for better standardization. Finally, attending physicians could not be blinded to the study group since the devices were clearly different. However, investigators were excluded from clinical decisions and randomization was employed to help reduce bias.

\section{Conclusions}

Among COPD patients with severe hypercapnic respiratory failure who received invasive ventilation, the use of HFNC as compared with NIV after extubation did not result in increased rates of treatment failure, while HFNC had better tolerance and comfort. These findings support the use of HFNC in such patients, especially for those who cannot tolerate NIV.

\footnotetext{
Abbreviations

COPD: Chronic obstructive pulmonary disease; NIV: Non-invasive ventilation; HFNC: High-flow nasal cannula oxygen therapy; PIC: Pulmonary infection control; ICU: Intensive care unit; APACHE II: Acute Physiological and Chronic Health Status Score II; SAPS II: Simplified Acute Physiology Score II; $\mathrm{PaCO}_{2}$ : Partial pressure of arterial carbon dioxide; $\mathrm{PaO}_{2}$ : Partial pressure of arterial oxygen; $\mathrm{FiO}_{2}$ : Fraction of inspired oxygen
}

\section{Acknowledgements}

None.

\section{Authors' contributions}

Conceived and designed the study: DT, JX JS, BL, and PG. Data acquisition: YX, PC, BL, XS, QZ, and YW. Analyzed the data: DT, JX, JS, QZ, PC, and BW. Wrote the paper: JS, DT, YW, XS, PC, BW, BL, YX, and JW. Revised the manuscript: DT, JX, PG, JS, and JW. All authors read and approved the final manuscript.

\section{Funding}

This work was supported by Rui E special fund for emergency medicine research (R2017003), Yangzhou Science and Technology Development Plan (YZ2018090), Yangzhou Phase III "Talent Cultivation Program" Support Project (2018034), and hospital-level support project of Northern Jiangsu People's Hospital (yzucms2018943, fcjs201708, fcjs201842).

\section{Availability of data and materials}

The datasets used and analyzed during the current study are available from the corresponding author in response to reasonable requests.

\section{Ethics approval and consent to participate}

This study was approved by the human subjects ethics committees of the two hospitals involved (2018KY-081 and 20180012), and informed consent was obtained from all enrolled patients or their relatives.

\section{Consent for publication}

Not applicable.

\section{Competing interests}

The authors declare that they have no competing interests.

\section{Author details \\ 'Department of Emergency Medicine, Clinical Medical College of Yangzhou University, Northern Jiangsu People's Hospital, Yangzhou 225001, China. \\ ${ }^{2}$ Accident and Emergency Medicine Academic Unit, The Chinese University of Hong Kong, Prince of Wales Hospital, Hong Kong SAR, China. ${ }^{3}$ Pharmacy Department, Clinical Medical College of Yangzhou University, Northern Jiangsu People's Hospital, Yangzhou 225001, China. ${ }^{4}$ Intensive Care Unit, Yangzhou Hongquan Hospital, Yangzhou 225200, China. ${ }^{5}$ Emergency Department, Peking Union Medical College Hospital, Chinese Academy of Medical Sciences, Beijing 100730, China.}

Received: 10 April 2020 Accepted: 28 July 2020

Published online: 06 August 2020

\section{References}

1. Boles JM, Bion J, Connors A, Herridge M, Marsh B, Melot C, Pearl R, Silverman H, Stanchina M, Vieillard-Baron A, et al. Weaning from mechanical ventilation. Eur Respir J. 2007;29(5):1033-56.

2. Heyland DK, Cook DJ, Griffith L, Keenan SP, Brun-Buisson C. The attributable morbidity and mortality of ventilator-associated pneumonia in the critically ill patient. The Canadian Critical Trials Group. Am J Respir Crit Care Med. 1999;159(4 Pt 1):1249-56.

3. Li PJ, Wang T, Xiao J, Jiang FM, Luo J, Shi CL, Liu GJ, Liang ZA. Efficacy of two noninvasive weaning strategies in intubated patients with chronic obstructive pulmonary disease: a meta-analysis and indirect treatment comparison. Heart Lung. 2016;45(2):132-9.

4. LV Y, LV Q, LV Q, Lai T. Pulmonary infection control window as a switching point for sequential ventilation in the treatment of COPD patients: a metaanalysis. Int J Chron Obstruct Pulmon Dis. 2017;12:1255-67.

5. Arnal JM, Texereau J, Garnero A. Practical insight to monitor home NIV in COPD patients. Copd. 2017;14(4):401-10.

6. Nava S, Ceriana P. Causes of failure of noninvasive mechanical ventilation. Respir Care. 2004:49(3):295-303.

7. Esteban A, Ferguson ND, Meade MO, Frutos-Vivar F, Apezteguia C, Brochard L, Raymondos K, Nin N, Hurtado J, Tomicic V, et al. Evolution of mechanical ventilation in response to clinical research. Am J Respir Crit Care Med. 2008; 177(2):170-7.

8. Gay PC. Complications of noninvasive ventilation in acute care. Respir Care. 2009;54(2):246-57 discussion 257-248. 
9. Jolliet P, Ouanes-Besbes L, Abroug F, Ben Khelil J, Besbes M, Garnero A, Arnal JM, Daviaud F, Chiche JD, Lortat-Jacob B, et al. A multicenter randomized trial assessing the efficacy of helium/oxygen in severe exacerbations of chronic obstructive pulmonary disease. Am J Respir Crit Care Med. 2017;195(7):871-80.

10. Frat JP, Thille AW, Mercat A, Girault C, Ragot S, Perbet S, Prat G, Boulain T, Morawiec E, Cottereau A, et al. High-flow oxygen through nasal cannula in acute hypoxemic respiratory failure. N Engl J Med. 2015;372(23):2185-96.

11. Braunlich J, Kohler M, Wirtz H. Nasal highflow improves ventilation in patients with COPD. Int J Chron Obstruct Pulmon Dis. 2016;11:1077-85.

12. Longhini F, Pisani L, Lungu R, Comellini V, Bruni A, Garofalo E, Laura Vega M, Cammarota G, Nava S, Navalesi P. High-flow oxygen therapy after noninvasive ventilation interruption in patients recovering from Hypercapnic acute respiratory failure: a physiological crossover trial. Crit Care Med. 2019;47(6):e506-11.

13. Ni YN, Luo J, Yu H, Liu D, Liang BM, Yao R, Liang ZA. Can high-flow nasal cannula reduce the rate of reintubation in adult patients after extubation? A meta-analysis. BMC Pulm Med. 2017;17(1):142.

14. Hernandez G, Vaquero C, Colinas L, Cuena R, Gonzalez P, Canabal A, Sanchez S, Rodriguez ML, Villasclaras A, Fernandez R. Effect of postextubation high-flow nasal cannula vs noninvasive ventilation on reintubation and postextubation respiratory failure in high-risk patients: a randomized clinical trial. JAMA. 2016;316(15):1565-74

15. Jing G, Li J, Hao D, Wang T, Sun Y, Tian H, Fu Z, Zhang Y, Wang X. Comparison of high flow nasal cannula with noninvasive ventilation in chronic obstructive pulmonary disease patients with hypercapnia in preventing postextubation respiratory failure: a pilot randomized controlled trial. Res Nurs Health. 2019;42(3):217-25.

16. Neumeier A, Keith R. Clinical guideline highlights for the hospitalist: the GOLD and NICE guidelines for the management of COPD. J Hosp Med. 2020;15(2):e1-2.

17. Borg G. Perceived exertion as an indicator of somatic stress. Scand J Rehabil Med. 1970;2(2):92-8.

18. Berkius J, Sundh J, Nilholm L, Fredrikson M, Walther SM. What determines immediate use of invasive ventilation in patients with COPD? Acta Anaesthesiol Scand. 2013:57(3):312-9.

19. Vogelmeier CF, Criner GJ, Martinez FJ, Anzueto A, Barnes PJ, Bourbeau J, Celli BR, Chen R, Decramer M, Fabbri LM, et al. Global strategy for the diagnosis, management, and prevention of chronic obstructive lung disease 2017 report. GOLD executive summary. Am J Respir Crit Care Med. 2017; 195(5):557-82.

20. Lightowler JV, Wedzicha JA, Elliott MW, Ram FS. Non-invasive positive pressure ventilation to treat respiratory failure resulting from exacerbations of chronic obstructive pulmonary disease: Cochrane systematic review and meta-analysis. BMJ. 2003;326(7382):185.

21. Collaborating Research Group for Noninvasive Mechanical Ventilation of Chinese Respiratory, S. Pulmonary infection control window in treatment of severe respiratory failure of chronic obstructive pulmonary diseases: a prospective, randomized controlled, multi-centred study. Chin Med J (Engl). 2005;118(19):1589-94.

22. Osadnik CR, Tee VS, Carson-Chahhoud KV, Picot J, Wedzicha JA, Smith BJ. Non-invasive ventilation for the management of acute hypercapnic respiratory failure due to exacerbation of chronic obstructive pulmonary disease. Cochrane Database Syst Rev. 2017;7:Cd004104.

23. Liu J, Duan J, Bai L, Zhou L. Noninvasive ventilation intolerance: characteristics, predictors, and outcomes. Respir Care. 2016;61(3):277-84.

24. Delclaux C, L'Her E, Alberti C, Mancebo J, Abroug F, Conti G, Guerin C, Schortgen $F$, Lefort $Y$, Antonelli $M$, et al. Treatment of acute hypoxemic nonhypercapnic respiratory insufficiency with continuous positive airway pressure delivered by a face mask: a randomized controlled trial. Jama. 2000;284(18):2352-60.

25. Braunlich J, Wirtz H. Nasal high-flow in acute hypercapnic exacerbation of COPD. Int J Chron Obstruct Pulmon Dis. 2018;13:3895-7.

26. Yuste ME, Moreno O, Narbona S, Acosta F, Penas L, Colmenero M. Efficacy and safety of high-flow nasal cannula oxygen therapy in moderate acute hypercapnic respiratory failure. Rev Bras Ter Intensiva. 2019;31(2):156-63.

27. Lee MK, Choi J, Park B, Kim B, Lee SJ, Kim SH, Yong SJ, Choi EH, Lee WY. High flow nasal cannulae oxygen therapy in acute-moderate hypercapnic respiratory failure. Clin Respir J. 2018;12(6):2046-56.

28. Sun J, Li Y, Ling B, Zhu Q, Hu Y, Tan D, Geng P, Xu J. High flow nasal cannula oxygen therapy versus non-invasive ventilation for chronic obstructive pulmonary disease with acute-moderate hypercapnic respiratory failure: an observational cohort study. Int J Chron Obstruct Pulmon Dis. 2019;14:1229-37.

29. Di Mussi R, Spadaro S, Stripoli T, Volta CA, Trerotoli P, Pierucci P, Staffieri F, Bruno F, Camporota L, Grasso S. High-flow nasal cannula oxygen therapy decreases postextubation neuroventilatory drive and work of breathing in patients with chronic obstructive pulmonary disease. Crit Care. 2018;22(1):180.

30. Stéphan F, Barrucand B, Petit P, Rézaiguia-Delclaux S, Médard A, Delannoy B, Cosserant B, Flicoteaux G, Imbert A, Pilorge C, et al. High-flow nasal oxygen vs noninvasive positive airway pressure in hypoxemic patients after cardiothoracic surgery: a randomized clinical trial. JAMA. 2015;313(23):2331-9.

31. Doshi P, Whittle JS, Bublewicz M, Kearney J, Ashe T, Graham R, Salazar S, Ellis TW Jr, Maynard D, Dennis R, et al. High-velocity nasal insufflation in the treatment of respiratory failure: a randomized clinical trial. Ann Emerg Med. 2018;72(1):73-83 e75.

32. Nishimura M. High-flow nasal cannula oxygen therapy in adults: physiological benefits, indication, clinical benefits, and adverse effects. Respir Care. 2016;61(4):529-41.

\section{Publisher's Note}

Springer Nature remains neutral with regard to jurisdictional claims in published maps and institutional affiliations.

\section{Ready to submit your research? Choose BMC and benefit from:}

- fast, convenient online submission

- thorough peer review by experienced researchers in your field

- rapid publication on acceptance

- support for research data, including large and complex data types

- gold Open Access which fosters wider collaboration and increased citations

- maximum visibility for your research: over $100 \mathrm{M}$ website views per year

At BMC, research is always in progress.

Learn more biomedcentral.com/submissions 